\title{
Mathematical Model Describes Treatment of Waste Water Using Modified Activated Carbon
}

\author{
A.S. Ibrahim*, A.S. AL Buloshi, S.S. AL Zaabi and L.A. AL Yafai \\ Chemical Engineering Department, Dhofar University, Salalah, Sultanate of Oman
}

Received 7 March 2016; Accepted 2 November 2016

\begin{abstract}
The proposed mathematical model covered in this paper includes the most important parameters associated with the rates of adsorption and desorption. Also, partial pressure is included since it is an important factor that affects rates of adsorption and desorption. The study focuses on the effects of the constant rates on adsorption of pollutant concentrations for benzene, nickel, cadmium, and copper using modified active carbon. When the rate constant of adsorption decreases, the pollutant concentration will also decrease, yielding high acceptable evidence of the logic of the proposed mathematical model. Also, the proposed model is compared with experimental data and other models to give good outcomes with high accuracy.
\end{abstract}

Keywords: Mathematical model, Waste water, Adsorption, Desorption, Activate carbon.

\footnotetext{
نموذج رياضي يصف معالجة مياه الصرف الصحي باستخدام الكريون النشط المعدل$$
\text { أ.س. إبراهيم”، أ. س. البلوشي، س. س. الزعبي و ل. أ. اليافعي }
$$

الملخص: النموذج الرياضي المقترح ِِّ هذه المقالة يحتوي على أهم البارامترات المصاحبة لمعدلات الامتصاص

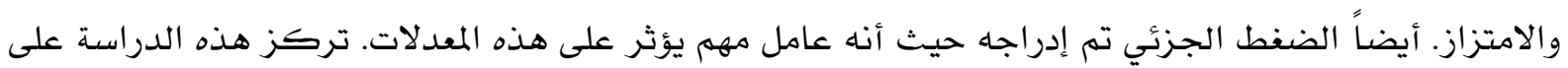

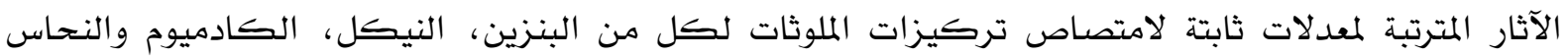

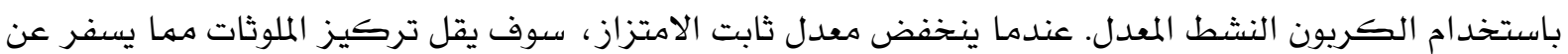

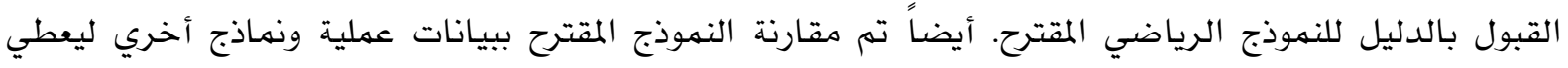
مخرجات ذات دقة عالية. الكلمات المفتاحية: النموذج الرياضي، مياه الصرف، الامتزاز، الامتصاص، الكريون النشط.

* Corresponding author's e-mail: ahmadsaadi47@yahoo.com
} 


\section{Nomenclature}

Symbol

A

$K_{a d, 1}^{+}$

CA.S

$\mathrm{C}_{\mathrm{A}}$

$\mathrm{C}_{\mathrm{Ai}}$

$\mathrm{C}_{\mathrm{V}}$

$K_{a d, 1}^{-}$

$K_{d, 1}^{-}$

$K_{a d, 1}^{+}$

$\mathrm{P}_{\mathrm{A}}$

$\mathrm{r}_{\mathrm{ad}}$

$\mathrm{r}_{\mathrm{d}}$

$\mathrm{r}_{\mathrm{A}}$

$S$

$\mathrm{V}_{\mathrm{i}}$

V

$\mathrm{t}$

$k_{f r}$

$\mathrm{n}$

$q_{e}$

$q_{\max }$

$C_{e}$

$K_{\text {Ln }}$

$C_{T M}$

$\mathrm{C}_{\text {TMI }}$

R

T

$k_{1}$

$q_{t}$

\section{Definition (unit)}

Waste water.

Rate constant for adsorption of forward direction.

Concentration of pollution of adsorption for surf modified activated carbon.

Concentration of adsorption.

Initial concentration of adsorption.

$\mathrm{V}$ modified activated carbon concentration.

Rate for constant adsorption of a reverse

direction.

Rate for constant desorption of a reverse direction.

Rate for constant desorption of a forward direction.

Partial pressure.

Rate of adsorption.

Rate of desorption.

Rate of adsorption.

Modified activated carbonative carbon.

Volumetric flow rate.

Volume.

Time (s)

Adsorption cap modified activated carbonity of the sorbent $\mathrm{mg} / \mathrm{g}(\mathrm{l} / \mathrm{mg})^{1 / n}$.

Freundlich's constants.

Amount of adsorbate adsorbed at equilibrium (mg/g).

Maximum monolayer adsorption cap modified activate carbonity of the adsorbent (mg/g).

Equilibrium concentration of adsorbate (mg/l).

Langmuir's adsorption constant related to free energy adsorption ( $1 / \mathrm{mg})$.

Temkin's constant related to the heat of sorption $(\mathrm{J} / \mathrm{mol})$.

Temkin's isotherm constant $(1 / \mathrm{g})$.

Gas constant (8.314 J/mol K).

Absolute temperature (K).

First-order rate constant $\left(\mathrm{min}^{-1}\right)$.

Amount of adsorbate adsorbed at any time (mg/g). 


\section{Introduction}

Waste water is one of the biggest pollution problems in the world, and suggestions for its treatment have been drawn from experimental and theoretical works. In experimental work, a simplified method for ion exchange has been used to evaluate kinetic data. Many techniques have been explored using modified activated carbontivated carbon to remove carbon dioxide. One of the most important techniques that has been used is semi-batch remodified activated carbonator fixed inside modified activated carbontivated carbon to adsorb methane and carbon dioxide (Prasetyo and Dod 1998). Another technique used biomass of sargassum fluitant to make bio sorption for heavy metals and tannin gel has been used to adsorb chromium (Nakano et al. 2001). Some special materials have been used to remove cadmium and mercury ions from aqueous solutions using sorption on treated Pinus pinaster bark (Vazquez et al. 2002). Numerous experimental studies have used rice husk as an adsorbent for waste water treatment (Ajmal et al. 2003), and chitosan-cellulose hydrogel beads have been used to adsorb copper ( $\mathrm{Li}$ and Bai 2005). Modified activated carbontivated carbon has been represented as one of the most effective modified activated carbontivated adsorption materials to be used to absorb carbon dioxide (Bog et al. 2006). Many researchers have used modified activated carbontivated carbon for waste water treatment (Afsaneh et al. 2008; Mohamed et al. 2008; Muhammad et al. 2008). A hybrid technique was used to produce a T-shirt model for waste water treatment.

Other exploratory works have explored waste water treatment options through a combination of experimental and theoretical work. The first adsorption mathematical model which was proposed in 1906 by Freundlich has been used in hetrogenous surf modified activated carbon adsorbent systems where the binding sites are not equivalent. A form of the Freundlich's model can be represented as follows:

$q_{e}=k_{f r} c_{e}^{1 / n}$

$\ln q_{e}=\ln k_{f r}+\frac{1}{n} \ln c_{e}$
The constants $k_{f r}$ and $n$ can be evaluated from the intercept and the slope of the linear plot of experimental data of $\ln q_{e}$ versus $\ln \mathrm{C}_{\mathrm{e}}$.

A second important mathematical model for adsorption is Langmuir's isotherm model (Okieimen and Ogbeide 2009), which depends on an isothermal state when all the sites are homogenous compare to Freundlish's model, and all these sites are filled by molecules to be adsorbed. The linear form of the Langmuir isotherm can be represented by the following equation:

$\frac{C_{e}}{q_{e}}=\frac{1}{\ln _{q_{\max }}^{k}}+\frac{C_{e}}{q_{\max }}$

The values of the constants $K_{L}$ and $q_{\max }$ can be evaluated from the intercept and the slope of the linear plot of experimental data of $C_{e} / q_{e}$ versus $C_{e}$.

Temkin and Pyzhev (Lalhruaitluanga et al. 2010) studied extensively the heat of adsorption and the adsorbate-adsorbent intermodified activated carbonation on adsorption isotherms. Temkin and Pyzhev's mathematical model can be represented as follows:

$q_{e}=C_{T M} \ln C_{T M I}+C_{T M} \ln C_{e}$

The constants $C_{T M I}$ and $C_{T M}$ can be determined from the intercept and the slope of the linear plot of the experimental data of $q_{e}$ versus $\ln C_{e}$. The values of the constants $C_{T M I}$ and $C_{T M}$ are listed in Table 1.

The Lagergren mathematical model is represented as proportional to the first power of sorption cap modified activated carbonity of the adsorbent and can be expressed as follows (Khaled et al. 2009).

Table 1. Langmuir, Freundlich and Temkin models' constants and correlation coefficients for sorption of methylene blue (MB) into modified activated carbon.

\begin{tabular}{llc}
\hline Isotherm & Parameters & Values \\
\hline Langmuir & $Q_{\mathrm{o}}(\mathrm{mg} / \mathrm{g})$ & 8.75 \\
& $K_{L n}(\mathrm{l} / \mathrm{mg})$ & 0.23 \\
Fruendlich & $K_{F r}$ & 4.21 \\
& $n$ & 4.13 \\
\multirow{4}{*}{ Temkin } & $C_{T M I}(\mathrm{l} / \mathrm{g})$ & 11.3 \\
& $C_{T M}$ & 1.5 \\
\hline
\end{tabular}




$$
\frac{d q_{t}}{d t}=k_{1}\left(q_{e}-q_{t}\right)
$$

Integrating Eq. (5) for the initial and end conditions $t=0$ to $t=t$ and $q_{t}=0$ to $q_{t}=q_{t}$, and, after some rearrangement, a linear plot is obtained:

$$
\log \left(q_{e}-q_{t}\right)=\log q_{e}-\frac{k_{1}}{2.303} t
$$

values of $k_{1}$ and $q_{e}$ were obtained from the slope and intercept, respectively. Table 2 lists Lagergren's mathematical model constants.

$$
\log \left(q_{e}-q_{t}\right)=\log q_{e}-\frac{k_{1}}{2.303} t
$$

Plots of $\log \left(q_{e}-q_{t}\right)$ versus $t$ for the Lagergren mathematical model where the values of $k_{1}$ and $q_{e}$ were obtained from the slope and intercept, respectively. Table 2 lists Lagergren's mathematical model constants.

\section{Methodology}

Deriving a mathematical model requires the provision of assumptions and a comparison with other models to create new ideas for a proposed model (Tables 3 and 4). Adsorption and desorption states represent active mechanisms for the system (Fig. 1) and can be derived as follows:

\subsection{Adsorption State}

This state depends on the properties of surface of adsorbent, partial pressure of fluid and rates constant of adsorption as seen in equations below:

$$
\begin{aligned}
& A_{1}+S \rightleftharpoons{ }_{K_{a d, 1}^{-}}^{K_{d, 1}^{+}} A_{1} \cdot S \\
& r_{a d}=K_{a d, 1}^{+}\left[P_{A} C_{V}-K_{a d, 1}^{-} C_{A_{1} \cdot S}\right. \\
& r_{a d}=K_{a d, 1}^{+}\left[P_{A} C_{V}-\frac{C_{A_{1} \cdot s}}{\frac{K_{a d, 1}^{+}}{K_{a d, 1}^{-}}}\right.
\end{aligned}
$$$$
\text { substitute (9) in (8) }
$$

$$
K_{a d}^{*}=K_{a d, 1}^{+} / K_{a d, 1}^{-}
$$

$$
\text { substitute (10) in (9) }
$$

Table 2. Correlation coefficients for adsorption of benzene on modified activated carbontivated carbon.

\begin{tabular}{c|c|c|c|c}
\hline $\begin{array}{c}\text { Initial } \\
\text { concentration } \\
10 \mathrm{~g} / 1\end{array}$ & \multirow{2}{*}{$\begin{array}{c}q_{\text {eexp. }} \\
(\mathrm{mg} / \mathrm{g})\end{array}$} & \multicolumn{3}{|c}{ Pseudo-first-order kinetic } \\
& & $\begin{array}{c}q_{\text {e cal. }} \\
\text { model }\end{array}$ & $\begin{array}{c}k_{1} \\
(1 / \mathrm{mg} / \mathrm{g})\end{array}$ & $R^{2}$ \\
\hline Benzene & 4.14 & 2.3 & 0.003 & 0.915 \\
Nickel & 6.31 & 3.8 & 0.003 & 0.898 \\
Copper & 6.53 & 4.21 & 0.0037 & 0.927 \\
Cadmium & 7.31 & 5.47 & 0.0028 & 0.934 \\
\hline
\end{tabular}

Table 3. The list of proposed mathematical model assumptions.

1. The fixed bed comprises liquid and solid phases.

2. No chemical remodified activate carbonation occurs inside a fixed bed.

3. Negligible radial temperature and concentration gradients exist in the fixed bed.

4. Adsorption occurs to adsorbent solid particles inside holes of modified activated carbon.

5. Desorption occurs to transfer solid particles from inside holes to the surf modified activated carbon of modified activated carbon.

6. Mass transfer occurs from surf modified activated carbon of modified activated carbon to the bulk flow.

7. The dynamics study is represented by the rates of adsorption and desorption at the surf modified activated carbon of modified activated carbon.

8. Heat transfer is considered in the new mathematical model. 
Table 4. Differences between the proposed mathematical model and the other models.

\begin{tabular}{|c|c|c|c|c|c|}
\hline No & Functions & $\begin{array}{l}\text { New Mathematical } \\
\text { model }\end{array}$ & $\begin{array}{l}\text { Langmuir } \\
\text { model }\end{array}$ & $\begin{array}{l}\text { Freundlich } \\
\text { isotherm } \\
\text { model }\end{array}$ & $\begin{array}{l}\text { Pseudo-first- } \\
\text { order model }\end{array}$ \\
\hline 1 & Phases & $\begin{array}{l}\text { Liquid, gas and } \\
\text { solid phase }\end{array}$ & Liquid phase & Liquid phase & Liquid phase \\
\hline 2 & Mass transfer & $\begin{array}{l}\text { Calculated without } \\
\text { chemical remodified } \\
\text { activate carbonation }\end{array}$ & Not calculated & $\begin{array}{l}\text { Not } \\
\text { calculated }\end{array}$ & $\begin{array}{l}\text { Calculated } \\
\text { without } \\
\text { chemical } \\
\text { remodified } \\
\text { activate } \\
\text { carbonation }\end{array}$ \\
\hline 3 & Adsorption & $\begin{array}{l}\text { Mass transfer from } \\
\text { surf modified } \\
\text { activate carbon to } \\
\text { the entrails holes of } \\
\text { modified activate } \\
\text { carbon without } \\
\text { chemical }\end{array}$ & Considered & Considered & Considered \\
\hline 4 & Desorption & $\begin{array}{l}\text { Mass transfer from } \\
\text { entrails holes of } \\
\text { MODIFIED } \\
\text { ACTIVATE } \\
\text { CARBON to the } \\
\text { surface activate } \\
\text { carbon without } \\
\text { chemical }\end{array}$ & Not considered & $\begin{array}{l}\text { Not } \\
\text { considered }\end{array}$ & $\begin{array}{l}\text { Not } \\
\text { considered }\end{array}$ \\
\hline 5 & Energy transfer & Considered & Not considered & $\begin{array}{l}\text { Not } \\
\text { considered }\end{array}$ & $\begin{array}{l}\text { Not } \\
\text { considered }\end{array}$ \\
\hline
\end{tabular}

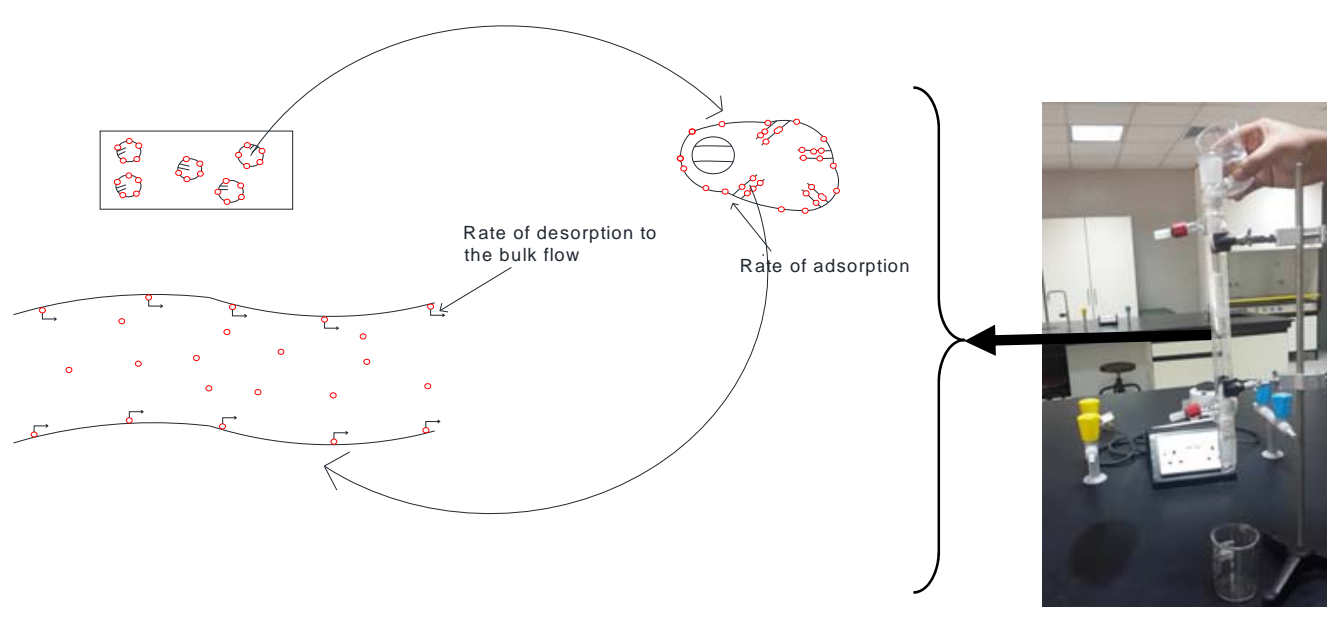

Figure 1. Steps of adsorption process.

\subsection{Desorption State}

This state depends on the same properties of adsorption but the molecules of adsorbent left to the bulk flow in opposite direction of adsorption's flowrate as seen in equations below:

$r_{a d}=K_{a d, 1}^{+}\left[P_{A_{1}} C_{V}-\frac{C_{A_{1} . S}}{K_{a d}^{*}}\right]$ 


$$
\begin{aligned}
& A_{1} \cdot S \rightleftharpoons{ }_{K_{S, 1}^{-}}^{K_{S}^{+}} A_{1}+S \\
& r_{d}=K_{S, 1}^{+} C_{A_{1} \cdot S}-K_{S, 1}^{-} P_{A_{1}} C_{V} \\
& r_{d}=K_{S, 1}^{+}\left[C_{A_{1} \cdot S} \frac{P_{A_{1}} C_{v}}{\frac{K_{S, 1}^{+}}{K_{S, 1}^{+}}}\right] \\
& K_{S}^{*}=\frac{K_{S, 1}^{+}}{K_{S, 1}^{-}}
\end{aligned}
$$

Let

$$
r_{d}=K_{S, 1}^{+}\left[C_{A_{1} \cdot S}-\frac{P_{A_{1}} C_{V}}{K_{S}^{*}}\right]
$$

The mechanism of the rate of adsorption can be controlled in all states of the system. Thus, this is the most important assumption.

$r d=0$. From equation (16)

$\mathrm{C}_{A_{1} . \mathrm{S}}=\frac{P_{A_{1}} C_{V}}{K_{S}^{*}}$

Substitute (17) in (11)

$$
\begin{aligned}
& r_{a d}=K_{a d, 1}^{+}\left[P_{A_{1}} C_{V}-\frac{P_{A_{1}} C_{V}}{K_{S}^{*} K_{a d}^{*}}\right] \\
& C_{T}=C_{A . S}=\frac{P_{A_{1}} C_{V}}{K_{S}^{*}} \\
& C_{V}=\frac{C_{T} K_{S}^{*}}{P_{A_{1}}}
\end{aligned}
$$

Substitute (20) in (18)

$$
\begin{aligned}
& r_{a d}=K_{a d, 1}^{+}\left[C_{T} K_{s}^{*}-C_{T} / K_{a d}^{*}\right. \\
& r_{a d}=K_{a d, 1}^{+} C_{T} K_{s}^{*}-C_{T} K_{a d}^{-}
\end{aligned}
$$

Representing the system as a continuous stirred-tank reactor (CSTR) process:

$\frac{V_{i}}{V}\left[C_{A i}-C_{A_{1}}\right]+r_{A}=\frac{d C_{A_{1}}}{d t}$

The volumetric flow rate compared to the volume of the system is very limited, so

$$
\frac{V_{i}}{V}=0
$$

Equation (22) will be $r_{a}=\frac{d c}{d t}$

The rate of remodified activate carbonation is represented as

$r_{a}=-r_{a d}=\frac{d c_{A_{1}}}{d t}$

Substitute equation (21) in (25)

$-\left[K_{a d, 1}^{+} C_{T} K_{s}^{*}-C_{T} K_{a d}^{-}\right]=\frac{d c_{A_{1}}}{d t}$

Solve equation (26)

$C_{A_{1}}=-\left[K_{a d, 1}^{+} C_{T} K_{s}^{*}-C_{T} K_{a d}^{-}\right] \mathrm{t}+$ constant

Boundary conduction

At $\mathrm{t}=0, \mathrm{C}_{A_{1}}=\mathrm{C}_{\mathrm{Ai}}$, constant $=C_{A i}$

Substitute in (21)

$C_{A_{1}}=-\left[K_{a d, 1}^{+} C_{T} K_{s}^{*}-C_{T} K_{a d}^{-}\right] \mathrm{t}+C_{\mathrm{Ai}}$

$C_{A_{1}}=C_{A i}-\mathrm{mt}$

Where $m=-C_{T}\left[K_{a d, 1}^{+} K_{s}^{*}-K_{a d}^{-}\right]$

\section{Results and Discussion}

The discussion that follows focuses on the experimental results associated with adsorbent benzene. The proposed mathematical model yielded good behavior for the experimental data from adsorbent benzene against the first order Lagergren model (Fig. 2).

Figure 3 shows results for adsorbent nickel using the proposed model and Lagergren model. Also, the proposed mathematical model was highly accurate, with results close to experimental data as compared to other models for copper and cadmium (Figs. 4 and 5, respectively).

Rates of adsorption and desorption have a big effect on pollutant concentrations. The rate of adsorption decreased the change of pollutant concentrations and also decreased the benzene, nickel, cadmium and copper (Figs. 6-9, respectively). 


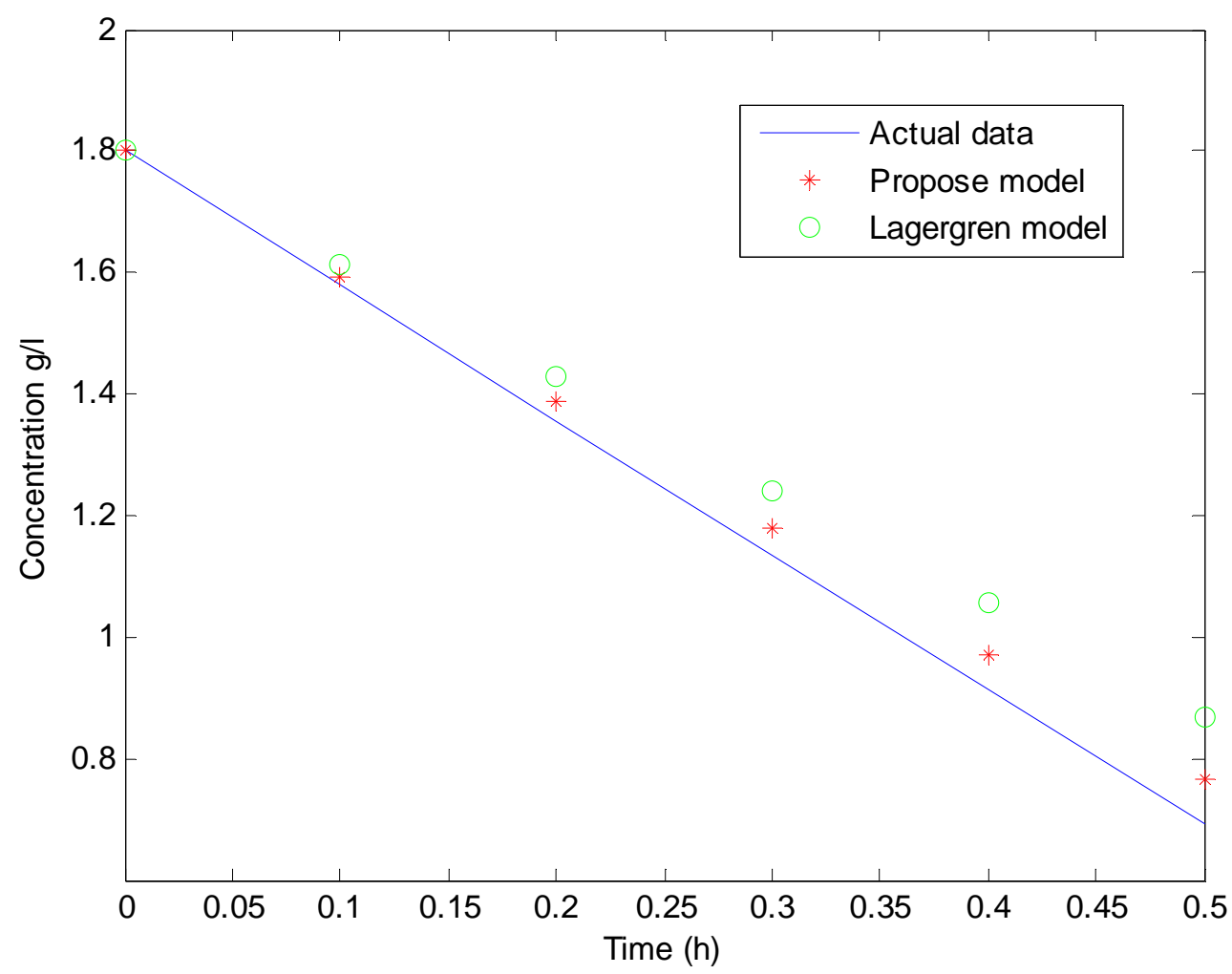

Figure 2. Comparison between proposed mathematical model and lagergren model for benzene.

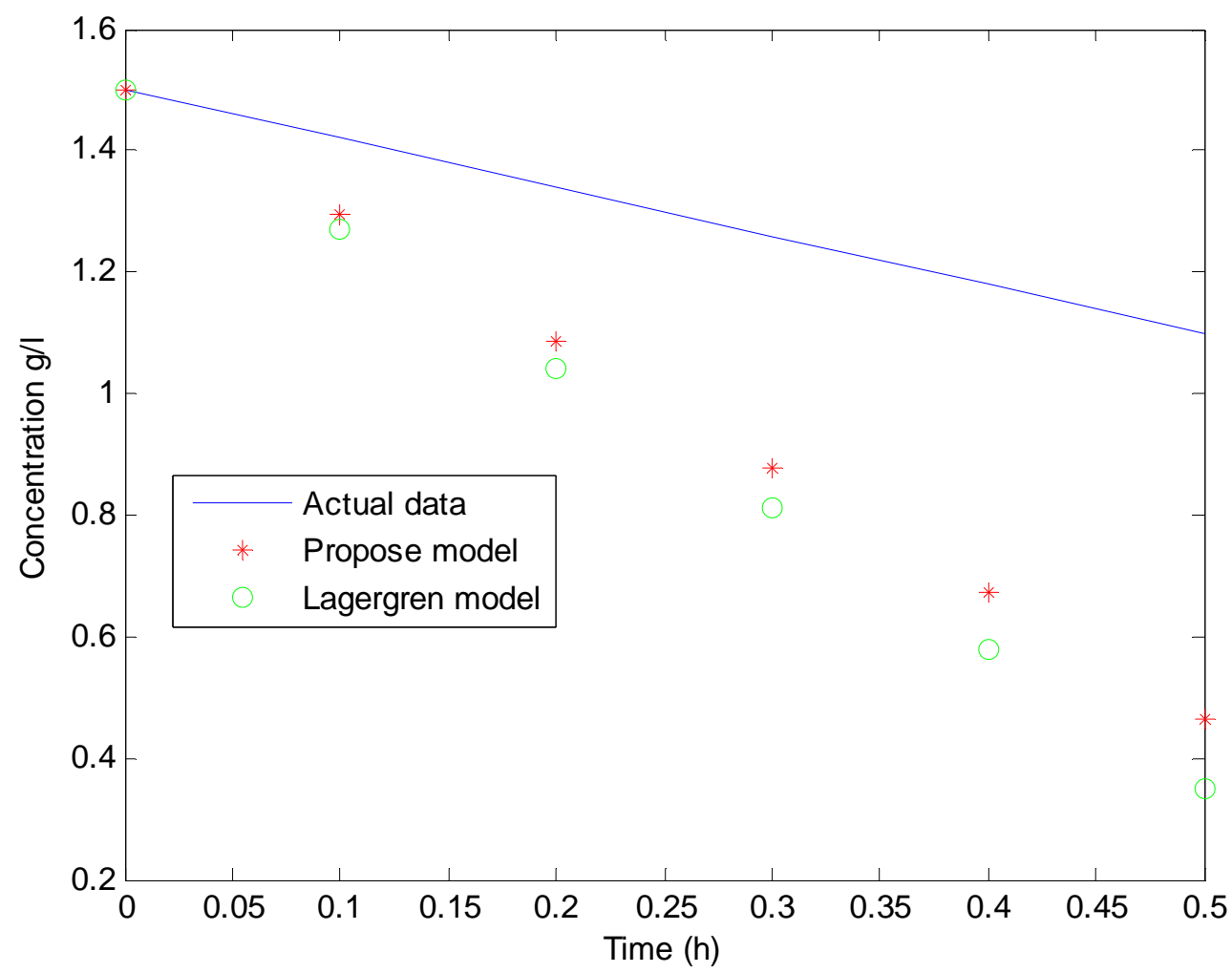

Figure 3. Comparison between proposed mathematical model and lagergren model for nickel. 


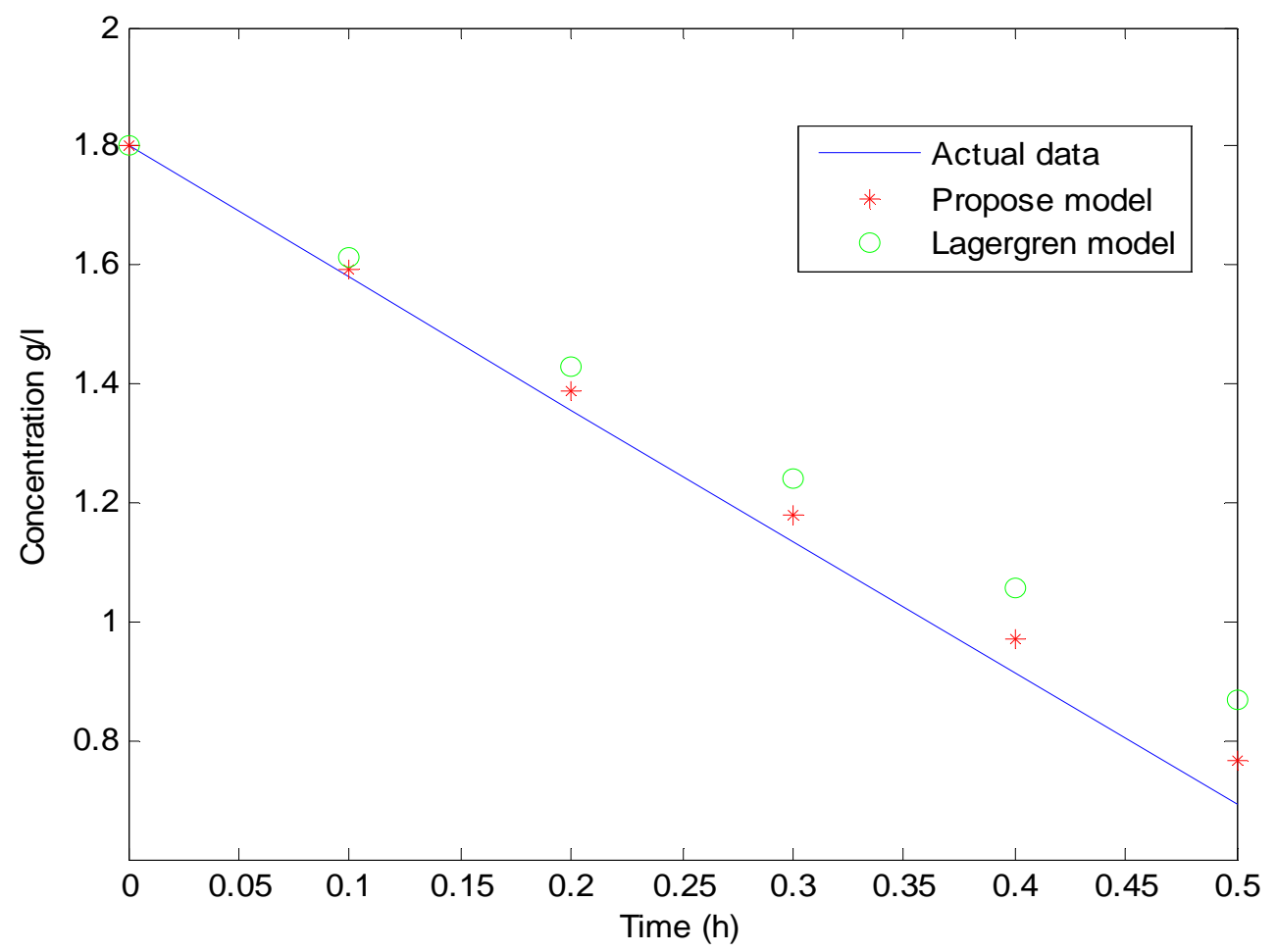

Figure 4. Comparison between proposed mathematical model and lagergren model for copper.

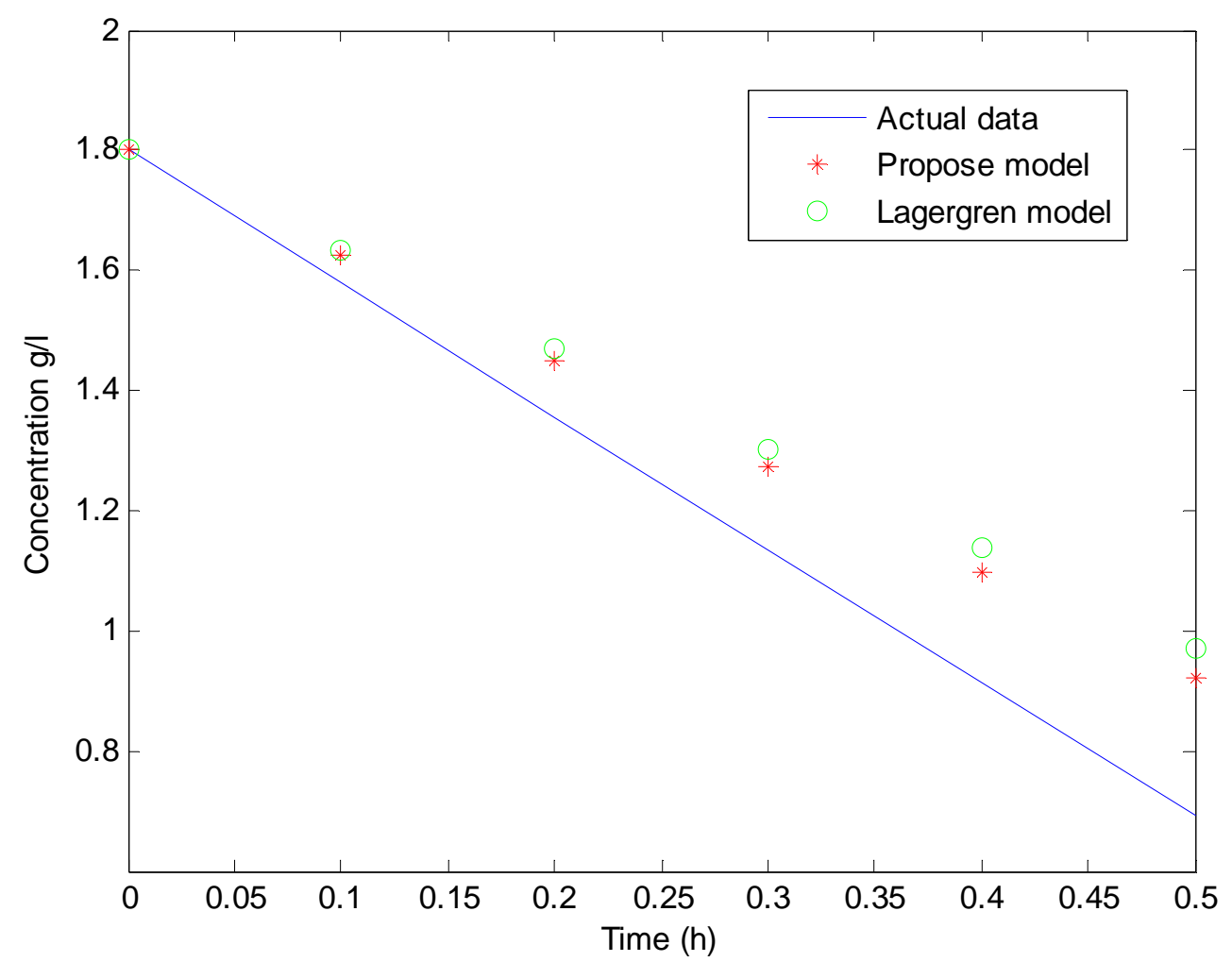

Figure 5. Comparison between proposed mathematical model and lagergren model for cadmium. 


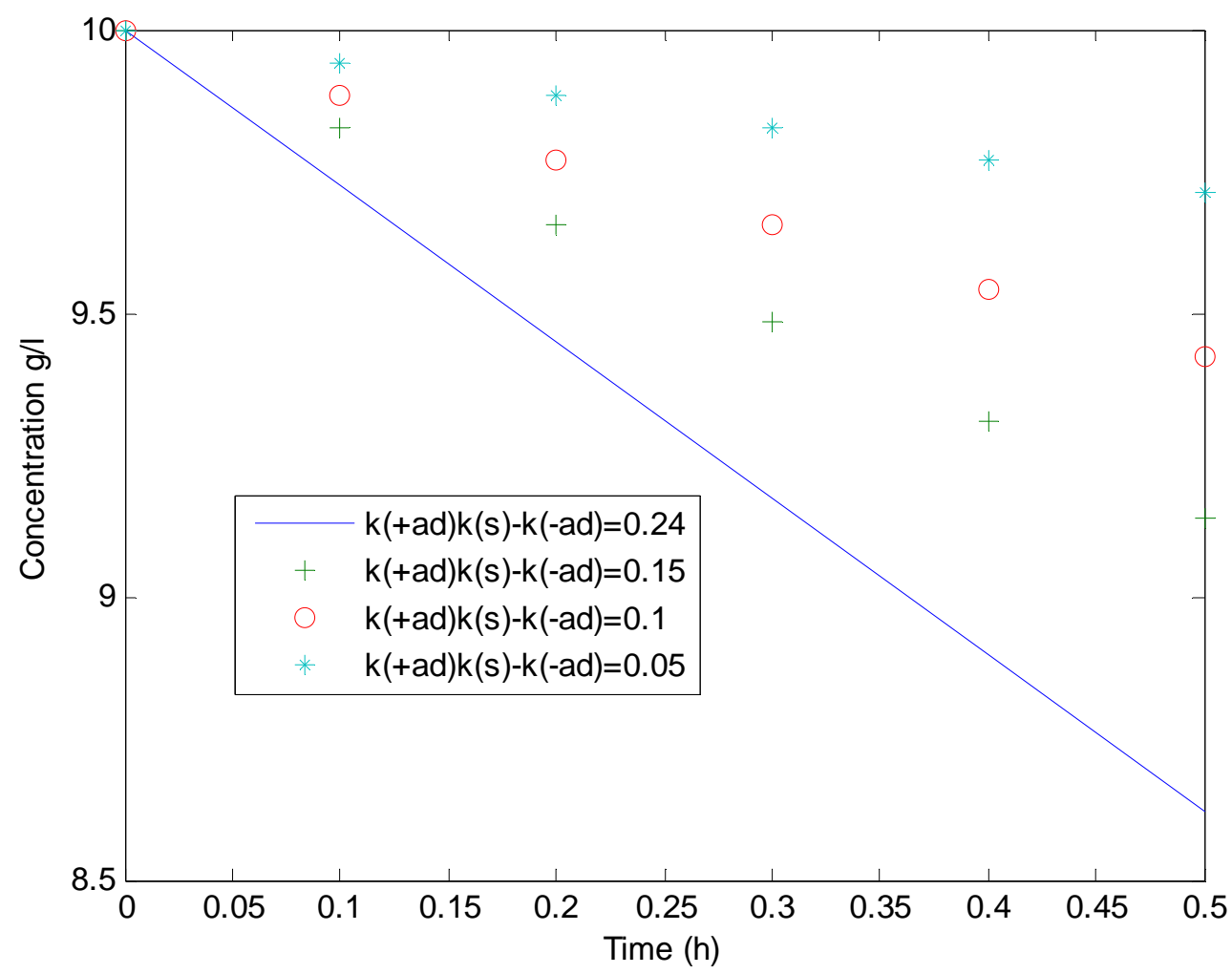

Figure 6. Effect of different rates of adsorption and desorption on pollutant concentration of benzene.

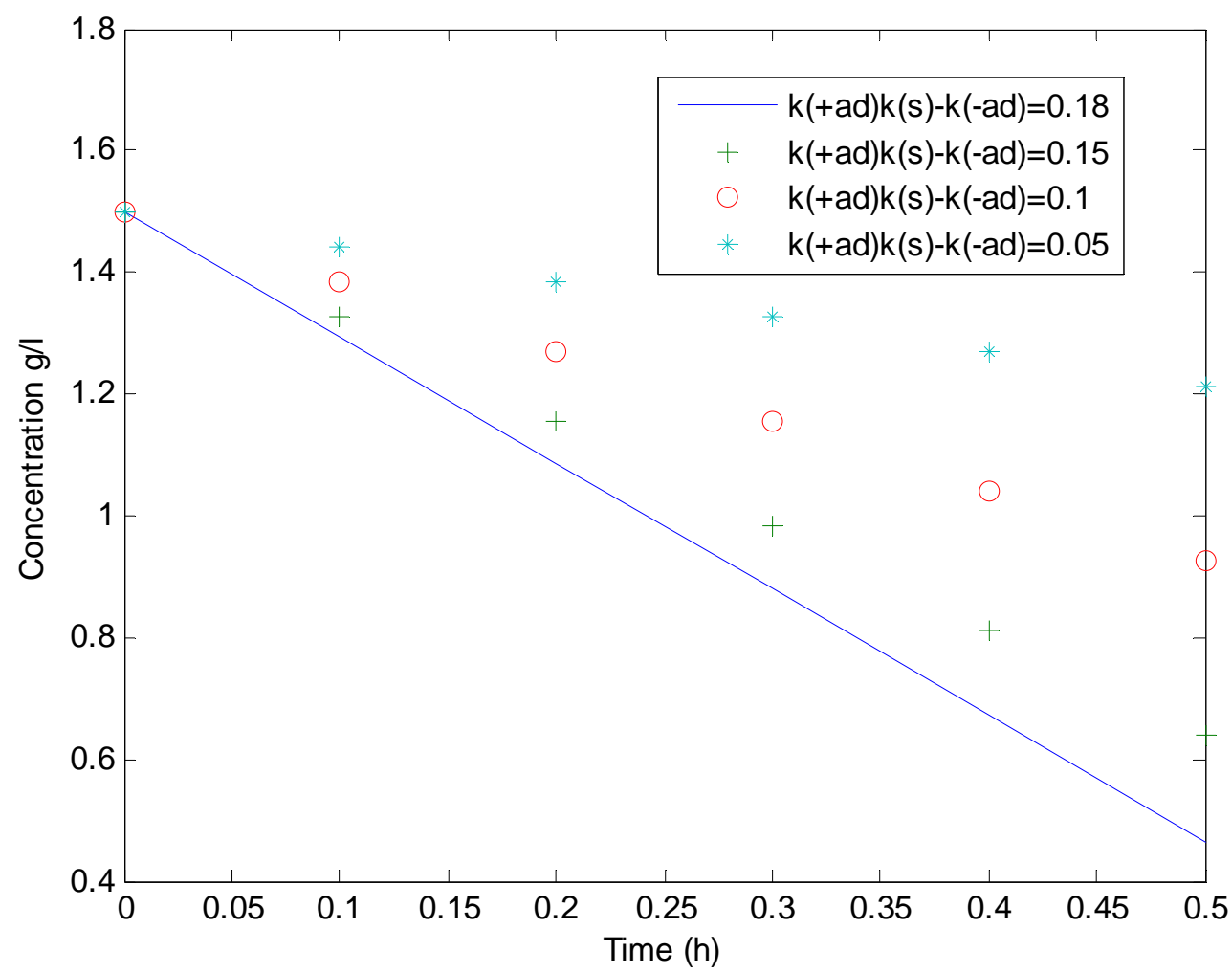

Figure 7. Effect of different rates of adsorption and desorption on pollutant concentration of nickel. 


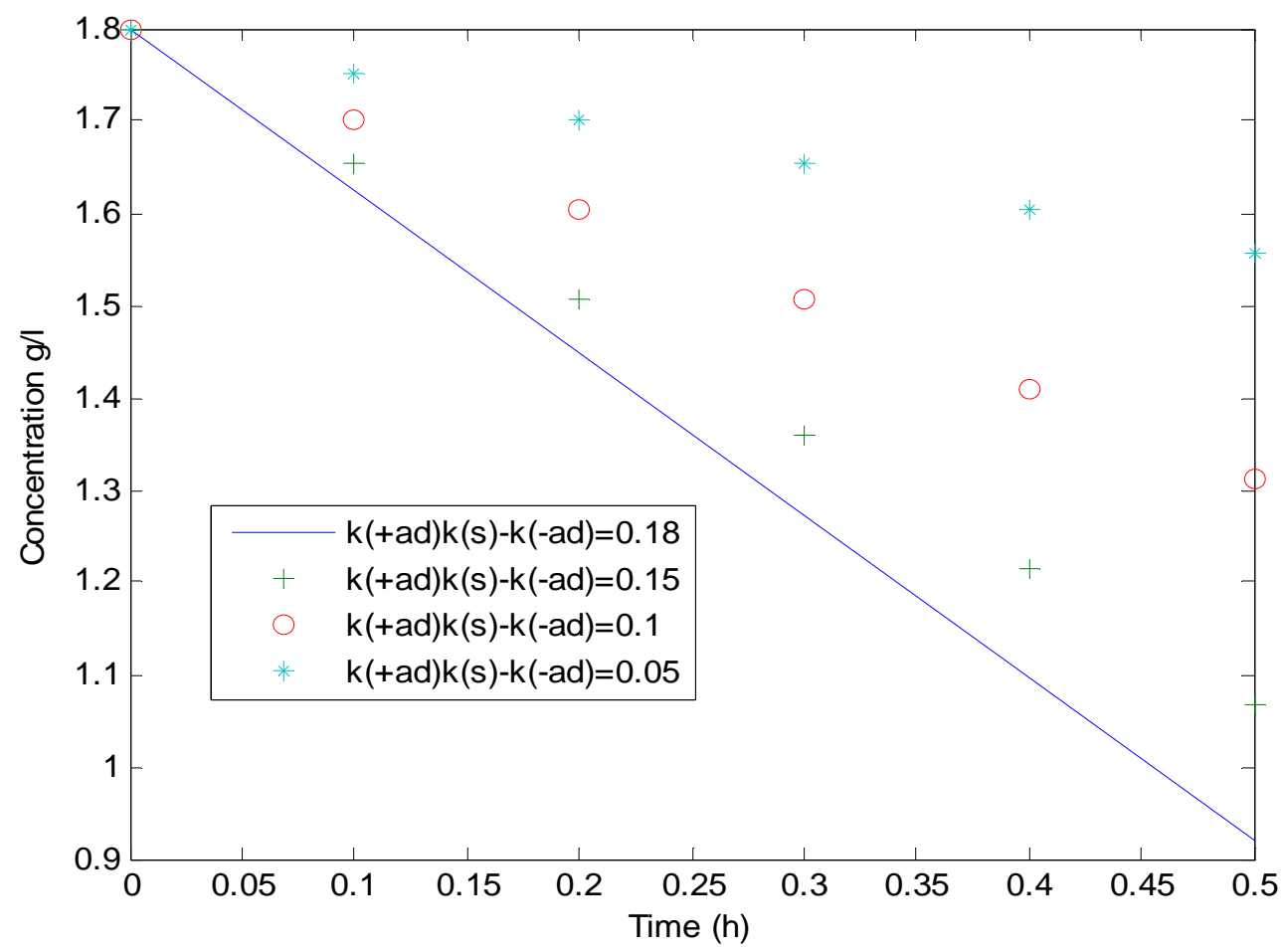

Figure 8. Effect of different rates of adsorption and desorption on pollutant concentration of cadmium.

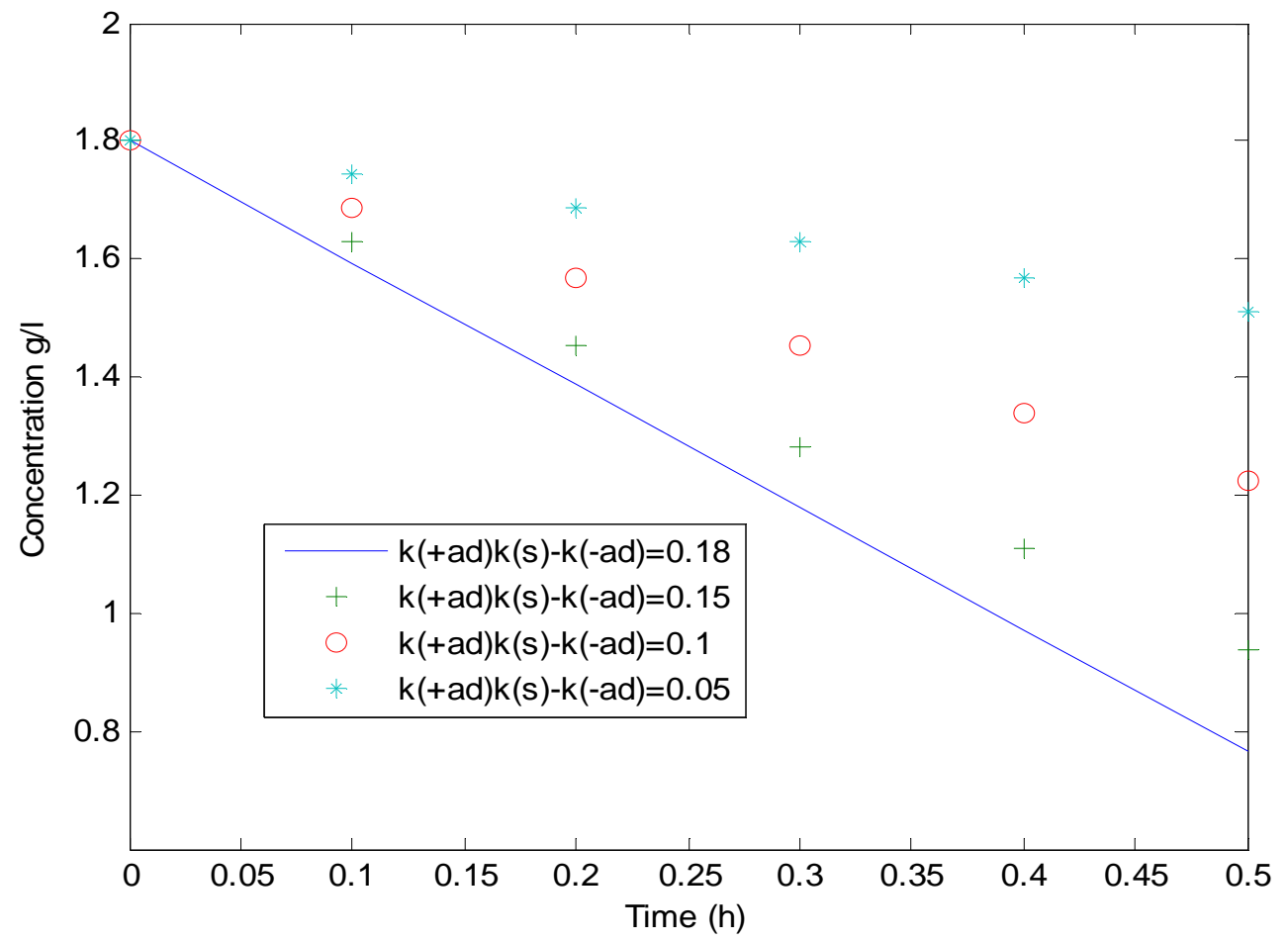

Figure 9. Effect of rates of adsorption and desorption on pollutant concentration of copper.

\section{Conclusion}

This proposed mathematical model has enough ability to evaluate dynamic adsorption and desorption for modified activate carbon to give clear view about mechanism of the system and very acceptable results due to inclusion of all 
the rates types for adsorption and desorption compare to the other models.

\section{References}

Afsaneh S, Mohammad R, Hosein D, Amin G, Mohammad H (2008), Adsorption of carbon dioxide using impregnated modified activate carbontivated carbon promoted by Zinc. International Journal of Greenhouse Gas Control 3: 249-254.

Ajmal M, Rak R, Jamal A, Ahmad R (2003), Adsorption studies on rice husk: removal and recovery of $\mathrm{Cd}$ (II) from wastewater. Bioresource Technology 86: 147-149.

Bog G, Liping C, Kechang X (2006), Adsorption of carbon dioxide on modified activate carbontivated Carbon. Journal of Natural Gas Chemistry 15: 223-229.

Lin N. Bai R (2005), Copper absorption on chitosan-cellulose hydrogel beads: hydrogel- beads: behaviors and mechanisms. Separation And Purification Technology 42: 237-247.

Lalhruaitluanga $\mathrm{H}$, Jayaram K, Prasad M, Kumar K (2010), Lead (II) adsorption from aqueous solutions by raw and modified activate carbontivated charcoals of melocanna modified activate carboncifera roxburgh (bamboo)-A comparative study. Journal of Hazardous Materials 175: 311-318.

Khaled A, Nemr A, Sikaily A, Abdelwahab O (2009), Treatment of artificial textile dye effluent containing Direct Yellow 12 by orange peel carbon. Desalination 238: 210232.

Mohamed K, Wan M, Chun Y, Donni A (2008),
Adsorption cap modified activate carbonites of carbon dioxide, oxygen, nitrogen and methane on carbon molecular basket derived from polyethyleneimine impregnation on microporous palm shell modified activate carbontivated carbon. Separation And Purification Technology 62: 609-613.

Muhammad R, Raziya N, Muhammad A, Tariq M, Khalil R (2008), Pb (II) biosorption from hazardous aqueous streams using gossypium hirsutum (Cotton) waste biomass. Journal of Hazardous Materials 161: 88-94.

Nakano Y, Takeshita K, Tsutsumi T (2001), Adsorption mechanim of hevalent chromium by Redox within CondensedTannin Gel, Water Research 35 :496-500.

Okieimen C, Ogbeide S (2009), The Dependence On Temperature of Carbonization and chemical modified activate carbontivation on charmodified activate carbonteristics of granular modified activate carbontivated carbon charmodified activate carbonteristics. Advanced Materials Research 62-64 : 398-403.

Prasetyo I, Dod D (1998), Adsorption rate of methane and carbon dioxide on modified activate carbontivated carbon by the semibatch constant molar flow rate method. Chemical Engineering Science 53(19): 3459-3467.

Vazquez G, Gonzalez A, Freire S, Lopez, Antorrena G (2002), Removal of cadmium and mercury ions from aqueous solution by sorption on treated pinus pinaster bark: kinetics and isotherms. Bioresource Technology 822: 47-51. 